\title{
Optimum Design and Cost Characteristic of Small Conveyor
}

\author{
${ }^{1}$ Suwat Nanetoe and ${ }^{2}$ Nitipong Soponpongpipat \\ ${ }^{1}$ Department of Industrial Engineering and Management, \\ ${ }^{2}$ Department of Mechanical Engineering, \\ Faculty of Engineering and Industrial Technology, Silpakorn University, Nakhon Pathom 73000, Thailand
}

Received 2012-06-26, Revised 2012-09-02; Accepted 2013-01-29

\begin{abstract}
Although there are many works dealing with the economic analysis of a long conveyor, the information about a short conveyor is insufficient. This study, thus, deals with the short conveyor by studying the effect of belt width, belt length, convey capacity, and conveyor inclination angle on the cost characteristic of short conveyor. The study was done by calculating the conveyor belt widths and their supports that could service a given convey capacity, conveyor length, and inclination angle. The cost of conveyor corresponding to each belt width was, later, determined. After the total cost of each conveyor had been already calculated, the lowest total cost of conveyor for a given convey capacity, inclination angle, and conveyor length was found. The relationships between the belt widths, belt length, convey capacity, inclination angle and the lowest total cost was, finally, analyzed. In addition, the increase of the lowest total cost, when an overdesign of convey capacity was made, was also investigated. The study was done by case study of conveyor of convey capacity of 50-500 ton $\mathrm{h}^{-1}$, the belt width of 400-1500 mm, the conveyor length of 10-100 m and conveyor inclination angle of 0 $30^{\circ}$. The results showed that the lowest total cost was found, for all given values, at the belt width range of 400-500 mm. The lowest total cost increased with the increase of the belt length. For normal convey capacity of 50 ton $\mathrm{h}^{-1}$, an overdesigned value of 50 ton $\mathrm{h}^{-1}$ caused the lowest total cost to increase more than $7 \%$ compared with the lowest total cost in case of normal convey capacity. For normal convey capacity more than 100 ton $\mathrm{h}^{-1}$, an overdesigned value of 50 ton $\mathrm{h}^{-1}$ made the increase of the lowest total cost less than $2 \%$.
\end{abstract}

Keywords: Economic Analysis, Short Conveyor, Conveyor Cost, Optimum Conveyor Design, Overdesign of Convey Capacity, Cost Characteristic

\section{INTRODUCTION}

Analyzing the total cost of the engineering system has to be done together with engineering design because designers will be able to set any sizes and shapes as long as they are proper for the engineering use. However, the various sizes and shapes contribute to different costs. As a result, the cost tells which size or shape is suitable to be applied. In other words, the optimum sizes and shapes are those that can contribute to the lowest total cost. There is a lot of research studying the effect of the total cost on the optimum size and shape in terms of engineering. (Jinghua et al., 2009; Ozel and Pihtili, 2007; Bolatturk, 2006; Soylemez and Unsal, 1999; Soponpongpipat et al., 2010; Yeunyongkul et al., 2010)

Conveyor design has been studied for a long time and there has been development on its design technique. For example, Tsalidi and Dentsoras (1997) illustrated the design of conveyor by applying design parameters space search technique. Fonseca et al. (2004) developed knowledge-based system for conveyor equipment selection. Moreover, there is study on conveyor characteristics and dynamic characteristics of conveyor belts (Hou and Meng, 2008). Zhang and Xia (2011) studied the energy efficiency optimization of

Corresponding Author: Nitipong Soponpongpipat, Department of Mechanical Engineering, Faculty of Engineering and Industrial Technology, Silapakorn University, Nakhon Pathom 73000, Thailand 
belt conveyors. In addition, the economic aspects for designing the conveyor were also described (Wheeler, 2008). The previous research presented economic analysis of the very long conveyor whose convey capacity was 500-3000 ton $\mathrm{h}^{-1}$. However, small and medium industrial factories use the convey capacity of $50-500$ tons/h with the belt length of $50-200 \mathrm{~m}$ and there have been few studies on the cost of this small conveyor. In addition, these small and medium industrial factories usually plan to increase their production capacity, which results in the preparation for increasing convey capacity to support future growth in production capacity. The cost analysis for the overdesign value of the convey capacity is different from the cost analysis for the usual case. As a result, this research showed the cost analysis of the small conveyor and the change of the lowest total cost because of effects from conveyor length and energy value running the conveyor. The research also shows cost characteristic for the overdesign value of convey capacity to support future growth in production capacity.

\section{MATERIALS AND METHODS}

\subsection{Engineering Design of the Conveyor}

The type of conveyor belt studied in this research was cotton/rayon staple. Steady-state design theory was applied to analyze conveyor tension, the number of ply and the size of driver set. Figure 1 shows the calculation process to design the conveyor. The calculation started from inputting convey capacity, conveyor length, properties of conveyed material, conveyor's inclination angle, angle of support wheel, detail of installation and properties of belt. After that, there was the calculation on each belt width to find out the number of ply, the conveyor driver power and the number of support wheel. The result from the calculation of each belt width was applied to analyze the total cost.

\subsection{Calculation of the Conveyor Cost}

The conveyor cost was calculated from the price and expenses of conveyor components which were designed from Fig. 1. The conveyor cost in this study was divided into 6 groups:

- The cost of belt support and components that are carrier roller, return bracket and belt cleaners

- Driver costs that are head and tail pulley, motor, gear box, drive and driven pulley, pulley belt, pulley shaft, bearing, driver housing and control system

- Conveyor frame cost

- Conveyor belt cost
- Energy cost

- Installation cost

Lifetime of the conveyor was determined from the component of which lifetime was longest, which was conveyor frame. The number of conveyor's components that were used for the whole lifetime of conveyor was determined by the quotient of the conveyor's lifetime and the lifetime of its components. The lifetime of each component is shown in Table 1.

As a result, the total cost of conveyor can be determined by Equation 1:

$\mathrm{C}=\sum \mathrm{s}_{\mathrm{i}} \mathrm{S}_{\mathrm{i}}+\sum \mathrm{d}_{\mathrm{i}} \mathrm{D}_{\mathrm{i}}+\mathrm{F}+\mathrm{bB}+\mathrm{E}+\mathrm{I}$

Where:

$\mathrm{C}=$ The total cost of conveyor.

$\mathrm{S}_{\mathrm{i}}=$ The number of components used for the whole lifetime in the group of belt support and components.

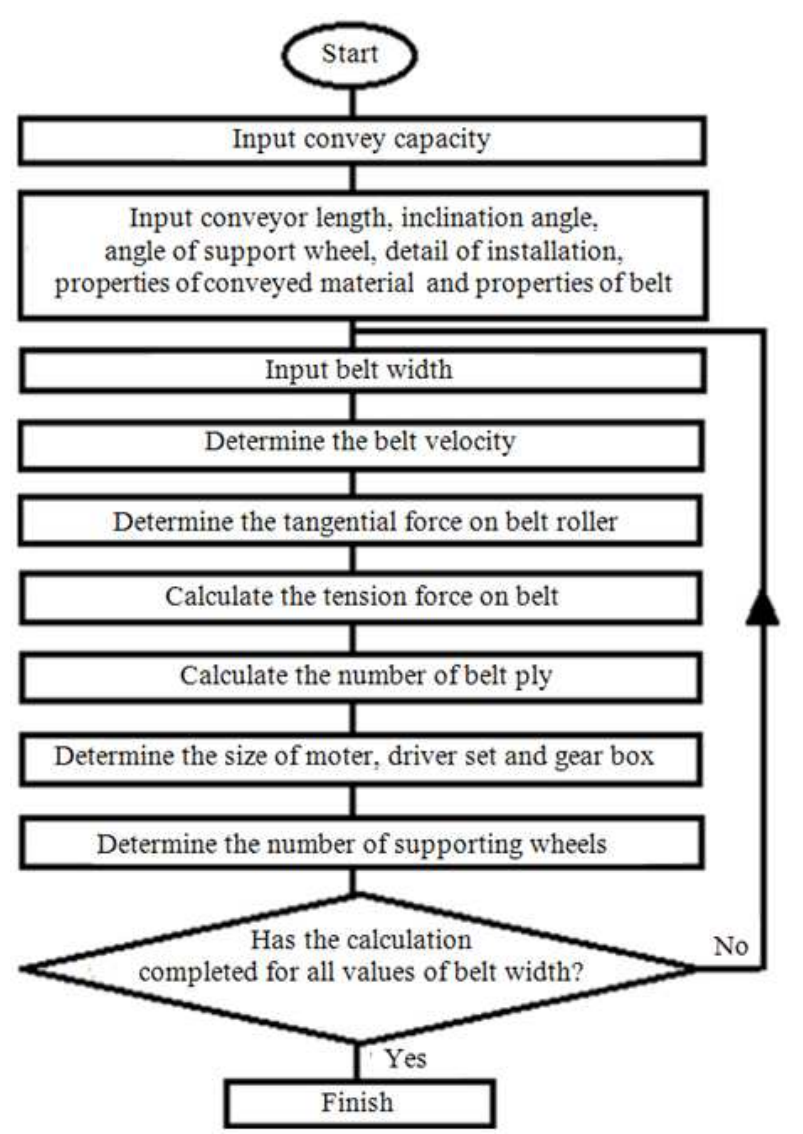

Fig. 1. The engineering calculation flow chart of the conveyor design 
Table 1. The lifetime of conveyor's components

\begin{tabular}{|c|c|c|c|c|}
\hline \multirow[b]{2}{*}{$\begin{array}{l}\text { Conveyor } \\
\text { components }\end{array}$} & \multicolumn{4}{|c|}{ Lifetime (year) } \\
\hline & $\begin{array}{l}\text { Slight } \\
\text { abrasion }\end{array}$ & $\begin{array}{l}\text { Moderate } \\
\text { abrasion }\end{array}$ & $\begin{array}{l}\text { Serious } \\
\text { abrasion }\end{array}$ & $\begin{array}{l}\text { Most serious } \\
\text { abrasion }\end{array}$ \\
\hline Conveyor belt & 5.00 & 4.00 & 3.0 & 2.00 \\
\hline Carrier roller & 3.00 & 2.50 & 2.0 & 1.16 \\
\hline Return bracket & 3.00 & 2.50 & 2.0 & 1.16 \\
\hline Head pulley & 7.00 & 6.00 & 5.0 & 4.00 \\
\hline Tail pulley & 7.00 & 6.00 & 5.0 & 4.00 \\
\hline $\begin{array}{l}\text { Bearing for } \\
\text { head pulley }\end{array}$ & 7.00 & 6.00 & 5.0 & 4.00 \\
\hline $\begin{array}{l}\text { Bearing for } \\
\text { tail pulley }\end{array}$ & 7.00 & 6.00 & 5.0 & 4.00 \\
\hline Gear box & $>8.00$ & $>7.00$ & $>6.0$ & $>5.00$ \\
\hline Motor & $>8.00$ & $>7.00$ & $>6.0$ & $>5.00$ \\
\hline Drive pulley & 6.00 & 6.00 & 6.0 & $>5.00$ \\
\hline Driven Pulley & 6.00 & 6.00 & 6.0 & $>5.00$ \\
\hline Pulley belt & 2.16 & 1.83 & 1.5 & 1.00 \\
\hline Conveyor frame & 10.00 & 10.00 & 10.0 & 10.00 \\
\hline
\end{tabular}

$\mathrm{S}_{\mathrm{i}}=$ The price of components in the group of belt support and components

$\mathrm{d}_{\mathrm{i}}=$ The number of components used for the whole lifetime in the group of driver set

$\mathrm{D}_{\mathrm{i}}=$ The price of components in the group of driver set.

$\mathrm{F}=$ The price of conveyor frame

$\mathrm{b}=$ The number of belts used for the whole life expectancy

$\mathrm{B}=$ The cost of belt

$\mathrm{E}=$ The cost of energy to run the conveyor

$\mathrm{I}=$ The installation cost

This research studied the belt that had the length of 10-100 $\mathrm{m}$, the width of 400-1500 $\mathrm{mm}$ and the inclination angle of $0-30^{\circ}$. The convey capacity was $50-500$ ton $\mathrm{h}^{-1}$, which was found in small conveyor.

\section{RESULTS}

\subsection{Optimum Belt Width in Terms of Engineering-Economics}

Figure 2 shows the relationship between the total cost of the conveyor and the belt width. The vertical axis shows the conveyor total cost (baht), while the horizontal axis shows the belt width $(\mathrm{mm})$. The convey capacity shown in the Fig. 2 is $50-500$ ton $\mathrm{h}^{-1}$. Figure $\mathbf{2 a - 2 b}$ show the calculation for the conveyor with the inclination angle of $0^{\circ}$, whose length is 10 and $100 \mathrm{~m}$ respectively, while Fig. 2c-2d show the calculation for the conveyor with the inclination of $20^{\circ}$.

It was found from Fig. 2a-2b that for every belt width and every conveyor inclination angle, with the convey capacity of 50 ton $\mathrm{h}^{-1}$, the belt width contributing to the lowest total cost of the conveyor was $400 \mathrm{~mm}$. It was also found that when the belt width increased, the total cost of the conveyor increased. When the convey capacity was higher than 50 ton $\mathrm{h}^{-1}$, the belt width contributing to the lowest total cost was $500 \mathrm{~mm}$. The total cost of conveyor tended to decrease when the belt width was increased from 400 to 500 $\mathrm{mm}$, while the total cost tented to increase when the belt width was larger than $500 \mathrm{~mm}$. This cost characteristic could be found for every conveyor length and inclination angle of 50 ton $\mathrm{h}^{-1}$ conveyor.

\subsection{The Effect of the Conveyor Length on the Lowest Total Cost}

Figure 4 shows the relationship between the conveyor length and the conveyor's lowest total cost for the convey capacity of 100 ton $\mathrm{h}^{-1}$. The horizontal axis shows the belt length (m), while the vertical axis shows the conveyor's lowest total cost (baht).

\subsection{The Effect of the Overdesign of Convey Capacity on the Change of the Conveyor's Lowest Total cost}

Figure 6a-6b show the relationship between the lowest total cost increasing and the normal convey capacity-the convey capacity before an overdesigned value of 50 ton $\mathrm{h}^{-1}$ was added. The vertical axis shows the increasing rate in percentage of the lowest total cost in case of the overdesigned capacity compared to the lowest total cost in case of the normal convey capacity. The horizontal axis shows the normal convey capacity.

\section{DISCUSSION}

\subsection{Optimum Belt Width in Terms of Engineering-Economics}

If the lowest total cost of conveyor was defined as the optimum point for engineering-economics aspect of belt width design, it can be seen from Fig. 2 that the optimum belt width could be divided into 2 categories. The first one was the optimum belt width without the turning point that occurred when the convey capacity was 50 ton $\mathrm{h}^{-1}$ and the other one was the optimum belt width with the turning point that occurred when the convey capacity was higher than 50 ton $\mathrm{h}^{-1}$. This was because of the effect from the cost of the energy used to run the conveyor. The evidence of explanation above could be seen in Fig. 3. The Figure shows the various costs of the conveyor with the convey capacity of 50 and 100 ton $\mathrm{h}^{-1}$ respectively. Both conveyors were $10 \mathrm{~m}$ long with the inclination angle of $0^{\circ}$. 
Suwat Nanetoe and Nitipong Soponpongpipat / American Journal of Applied Sciences, 10 (1): 15-23, 2013

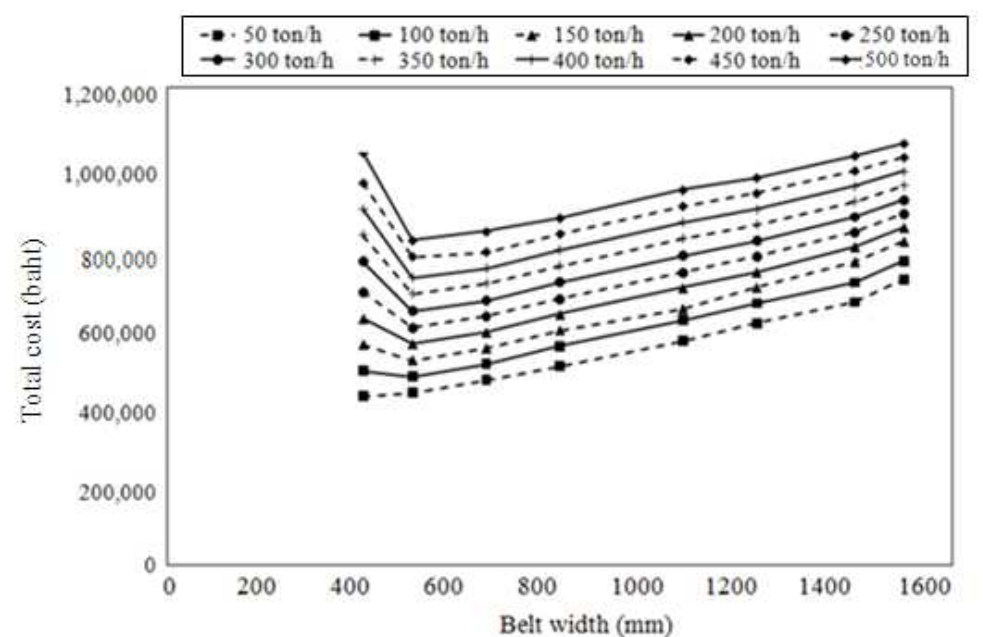

(a)

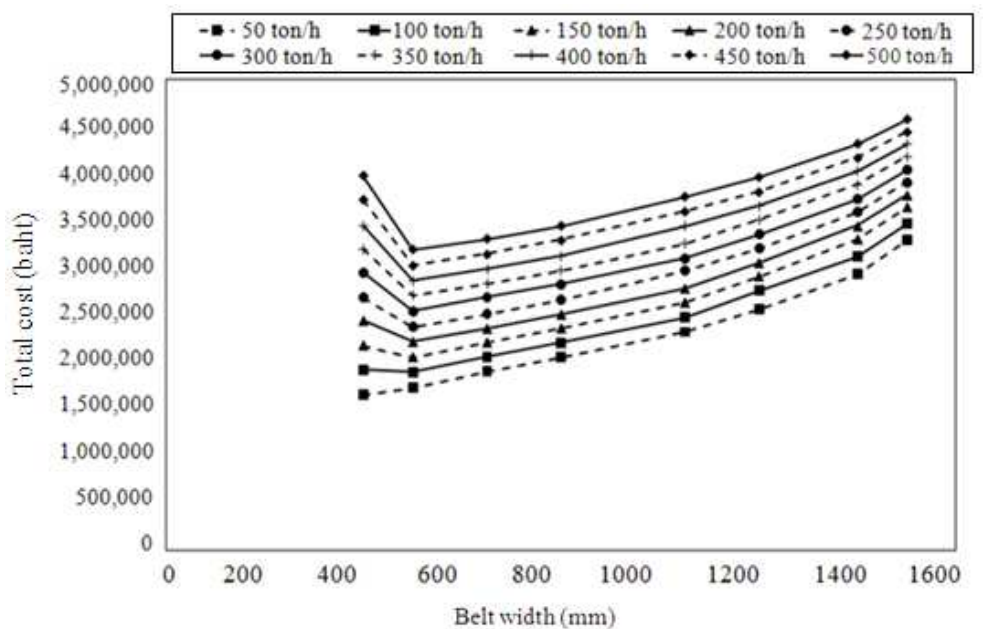

(b)

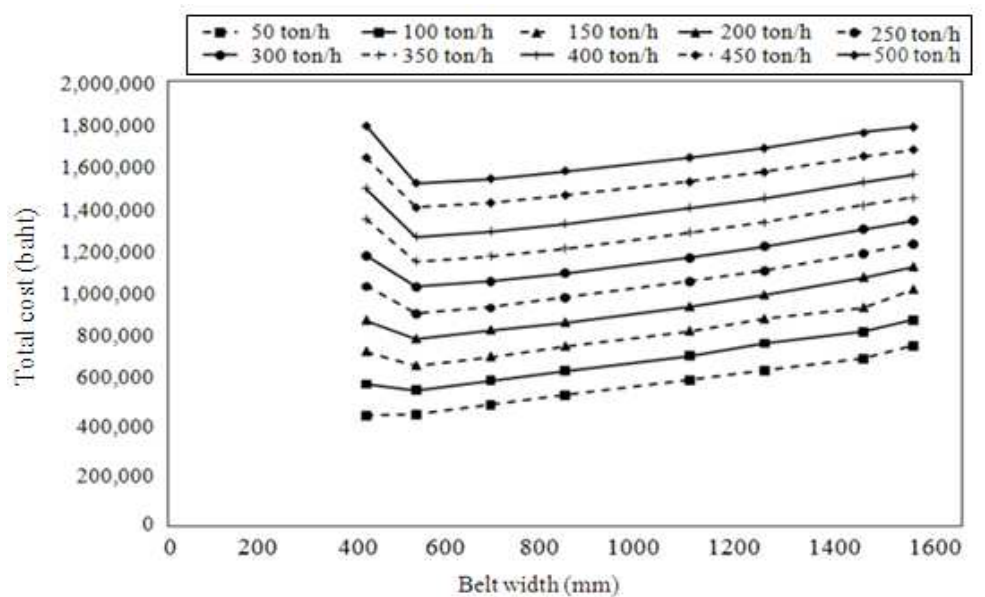

(c) 
Suwat Nanetoe and Nitipong Soponpongpipat / American Journal of Applied Sciences, 10 (1): 15-23, 2013

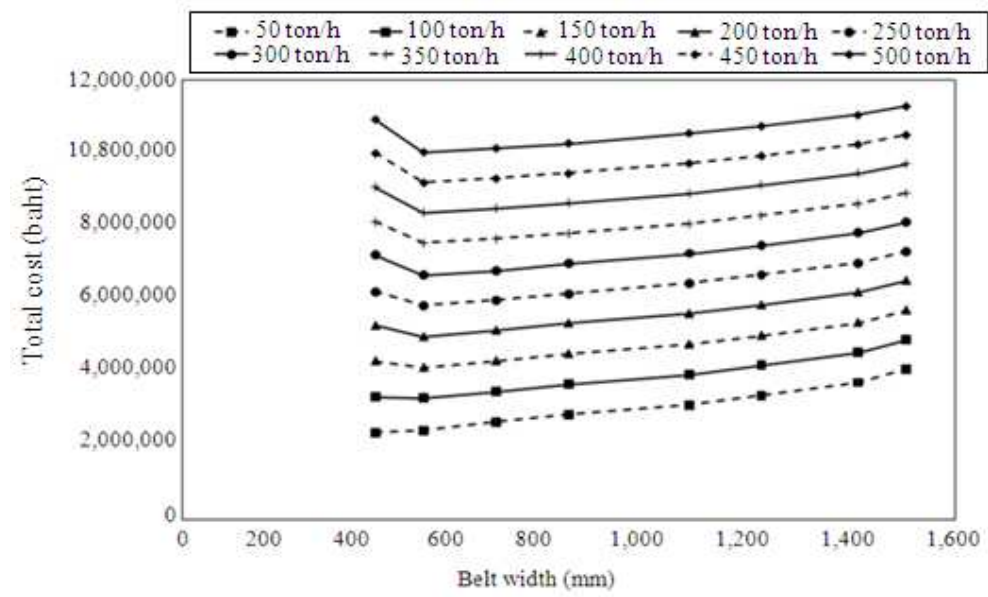

(d)

Fig. 2. The relationship between the total cost of conveyor and the belt width (a) belt length: $10 \mathrm{~m}$; inclination angle: $0^{\circ}$, (b) belt length: $100 \mathrm{~m}$; inclination angle: $0^{\circ}$, (c) belt length: $10 \mathrm{~m}$; inclination angle: $20^{\circ}$, (d) belt length: $100 \mathrm{~m}$; inclination angle: $20^{\circ}$

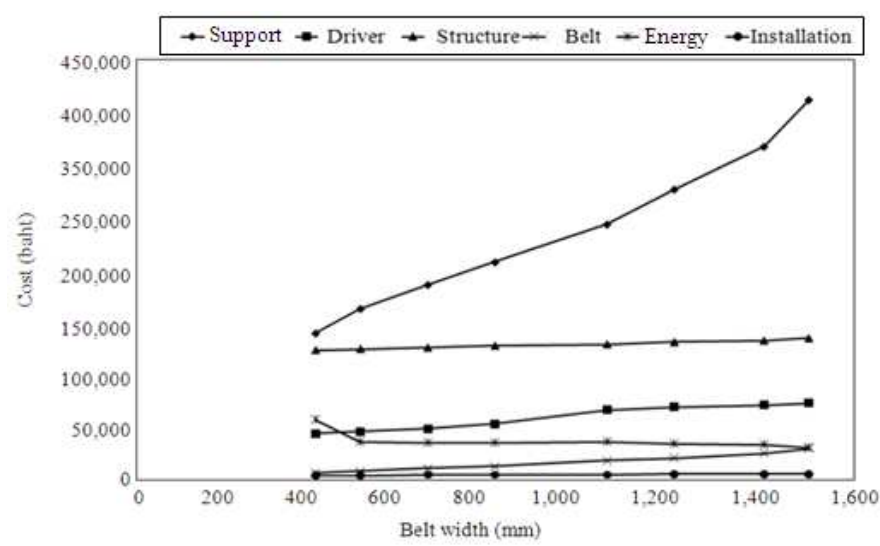

(a)

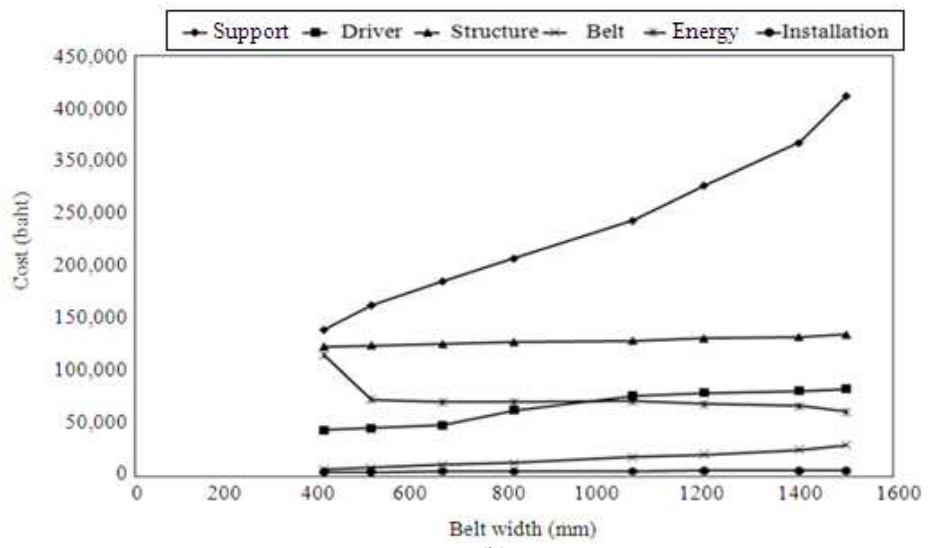

(b)

Fig. 3. The various costs for the belt length of $10 \mathrm{~m}$ with the inclination angle of $0^{\circ}$ (a) convey capacity: 50 ton $\mathrm{h}^{-1}$ (b) convey capacity: 100 ton $^{-1} \mathrm{~h}$ 
Suwat Nanetoe and Nitipong Soponpongpipat / American Journal of Applied Sciences, 10 (1): 15-23, 2013

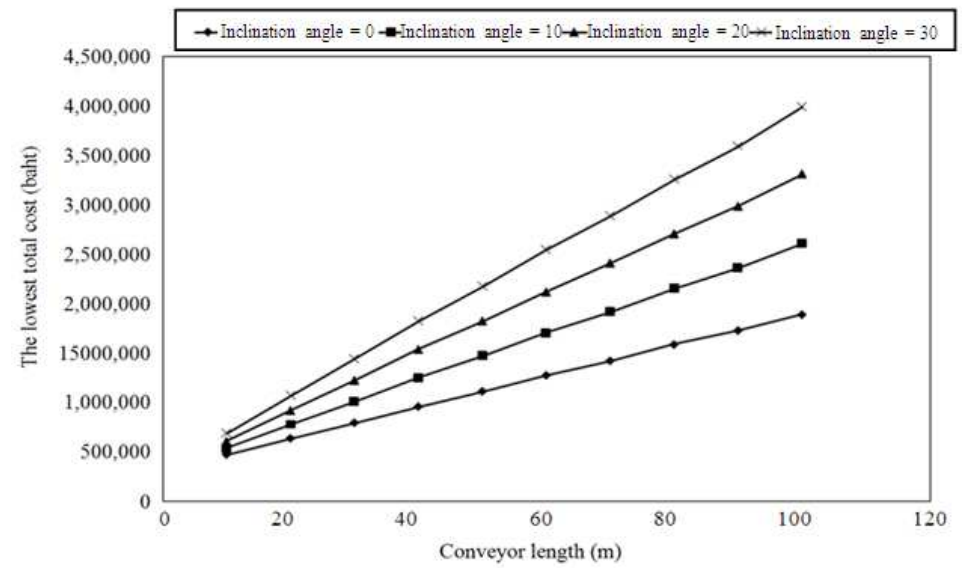

Fig. 4. The effect of the conveyor length on the lowest total cost at various inclination angles for the conveyor with the convey capacity of 100 ton $\mathrm{h}^{-1}$

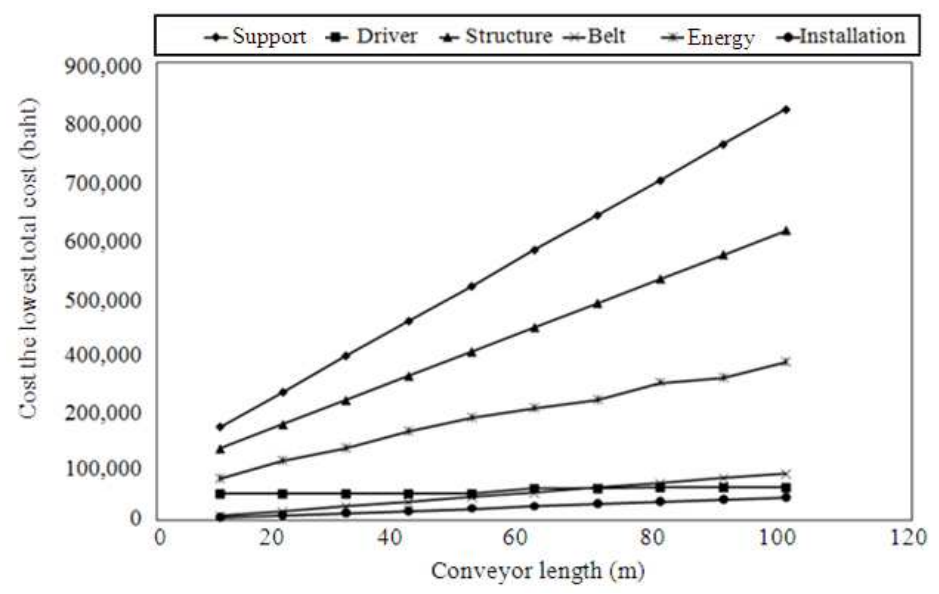

Fig. 5. The relationship between the various costs of conveyor and the belt length for the conveyor with the convey capacity of 100 ton $\mathrm{h}^{-1}$ and the inclination angle of $0^{\circ}$

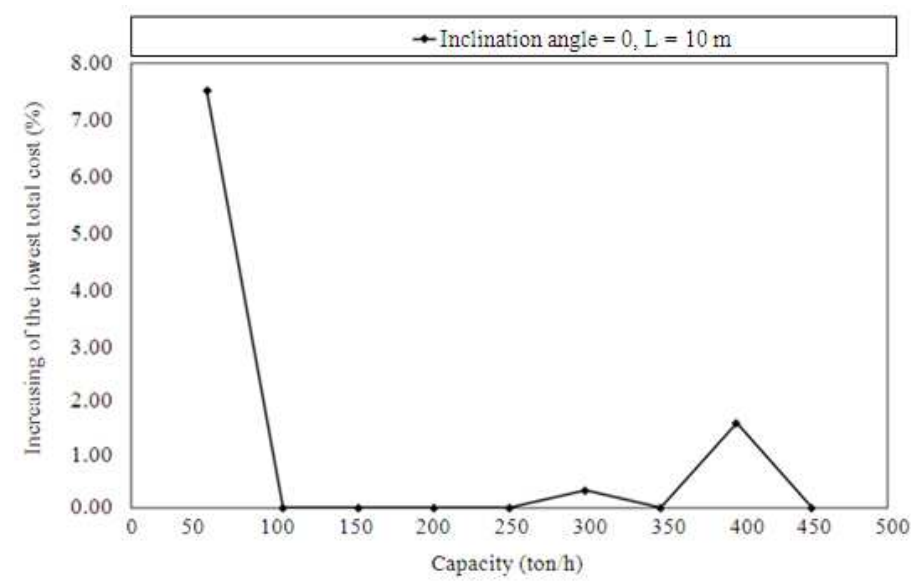

(a) 
Suwat Nanetoe and Nitipong Soponpongpipat / American Journal of Applied Sciences, 10 (1): 15-23, 2013

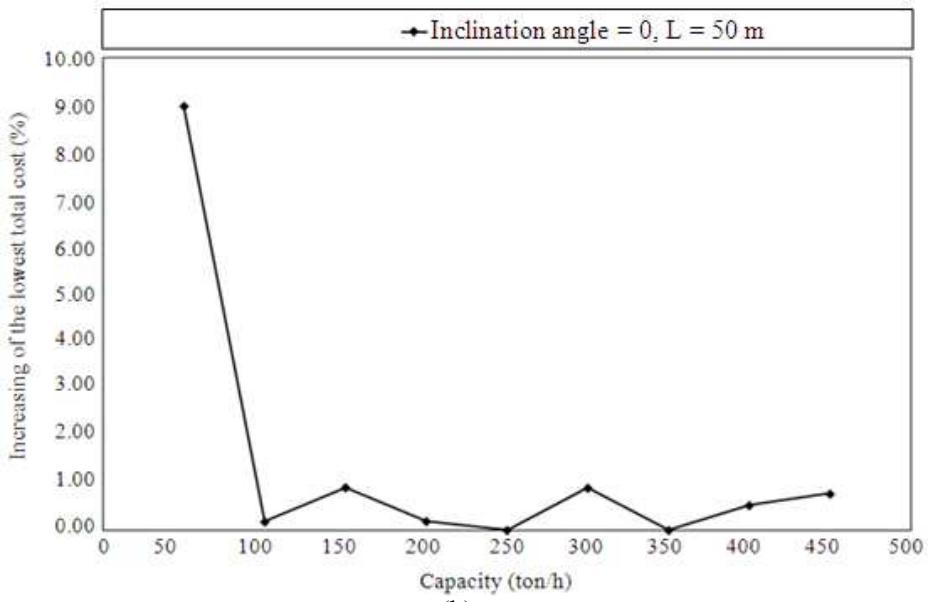

(b)

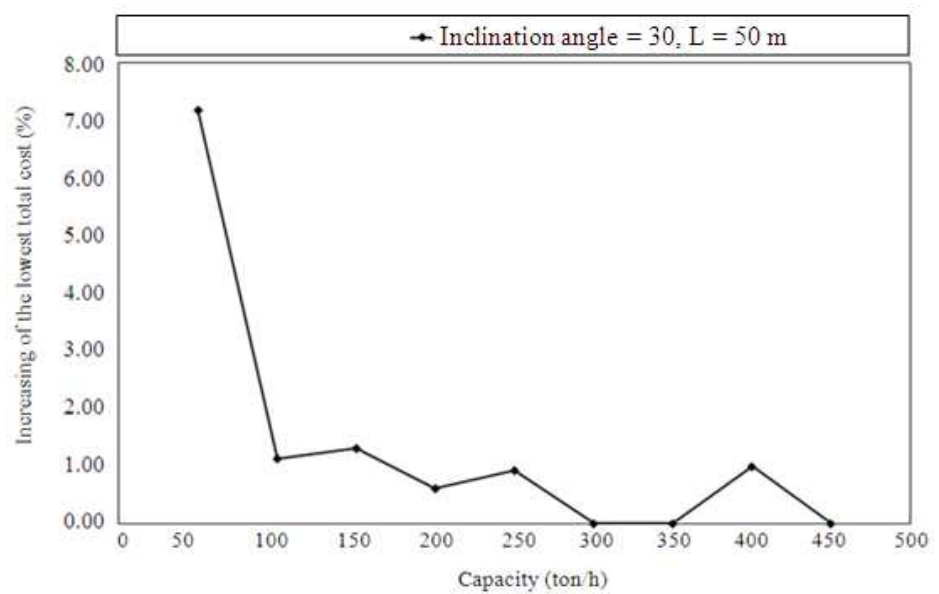

(c)

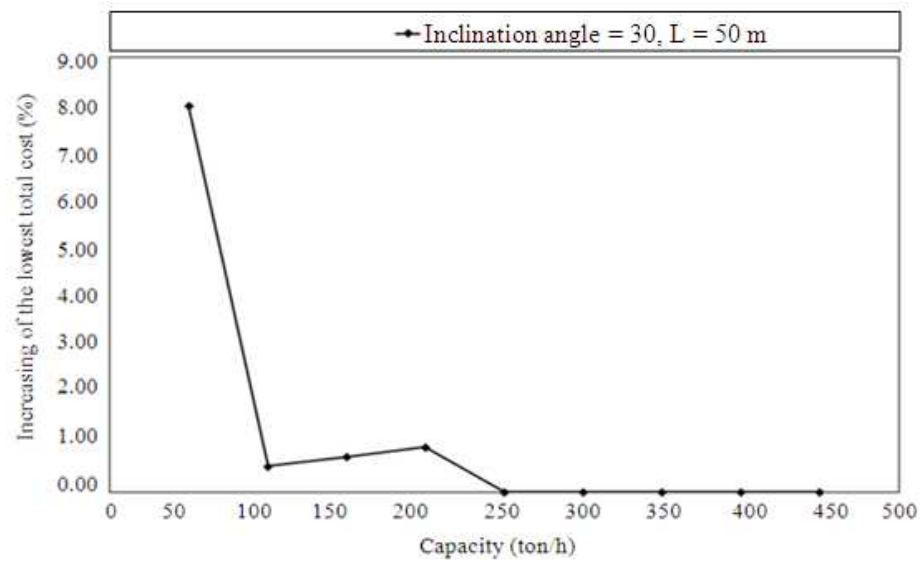

(d)

Fig. 6. The relationship between the lowest total cost increasing and the normal convey capacity when there was the overdesign value of 50 ton $\mathrm{h}^{-1}$, (a) belt length: $10 \mathrm{~m}$; inclination angle: $0^{\circ}$ (b) belt length: $50 \mathrm{~m}$; inclination angle: $0^{\circ}$ (c) belt length: 50 $\mathrm{m}$; inclination angle: $30^{\circ}$ (d) belt length: $100 \mathrm{~m}$; inclination angle: $30^{\circ}$ 
It could be seen that when the convey capacity was 50 ton $\mathrm{h}^{-1}$, the decreasing rate of the energy cost of the conveyor with belt width range from 400 to $500 \mathrm{~mm}$ was lower than the increasing rate of other costs. As a result, the total cost of the conveyor increased with the increasing width of the belt and the total cost was lowest at the belt width of $400 \mathrm{~mm}$ that was the lowest width used for calculation. When the convey capacity was higher than 50 ton $\mathrm{h}^{-1}$, the decreasing rate of the energy cost of the conveyor with belt width range from 400 to $500 \mathrm{~mm}$ was higher than the increasing rate of other costs, while the decreasing rate of the energy cost was lower than the increasing rate of other costs when the belt width was higher than $500 \mathrm{~mm}$. As a result, the turning point of the total cost was found at the belt width of $500 \mathrm{~mm}$, causing the belt width of $500 \mathrm{~mm}$ to become the lowest total cost of the conveyor.

It could be concluded that the optimum belt width of conveyor could be classified into 2 cases. The first one was the optimum belt width without the turning point of the total cost that occurred when the convey capacity was 50 ton $\mathrm{h}^{-1}$. For this case, the optimum belt width that made the lowest total cost was $400 \mathrm{~mm}$. The other one was the optimum belt width with the turning point of the total cost that occurred when the convey capacity was higher than 50 ton $\mathrm{h}^{-1}$. The lowest total cost of the conveyor occurred at the turning point of the total cost and it was the belt width of $500 \mathrm{~mm}$ for every length and inclination angle. This was because of the effect of the energy cost.

\subsection{The Effect of the Conveyor Length on the Lowest Total Cost}

Before further discussion was conducted, it should be recognized that the lowest total cost occurred only at the optimum belt width. From the Fig. 4, it could be seen that the conveyor's lowest total cost increased in linear relationship with the increasing conveyor length. This was because when the conveyor was longer, the various cost of conveyor tended to increase linearly, as can be seen in the conveyor with the convey capacity of 100 ton $\mathrm{h}^{-1}$ and the inclination angle of $0^{\circ}$ shown in Fig. 5 .

It was found that when the conveyor length increased, the conveyor's lowest total cost increased linearly.

\subsection{The Effect of the Overdesign of Convey Capacity on the Change of the Conveyor's Lowest Total cost}

For the small conveyor, the user might need to increase the convey capacity in the future or sometimes need to temporarily increase the convey capacity. For this situation, it may be preferred to overdesign the convey capacity. This part analyzes the change of the lowest total cost when an overdesign of the convey capacity was conducted. It could be seen from the Fig. 6a6b that when an overdesigned value of 50 ton $\mathrm{h}^{-1}$ was added to the normal convey capacity design of 50 ton $\mathrm{h}^{-1}$, it caused the conveyor's lowest total cost to increase more than $7 \%$. With an overdesigned value of 50 ton $\mathrm{h}^{-1}$ added to normal convey capacity of 100 ton $\mathrm{h}^{-1}$ upward, the lowest total cost increased not more than $2 \%$. This kind of tendency could be found in other inclination angles as well, as shown in Fig. 6c-6d.

\section{CONCLUSION}

This research studies the optimum conveyor design in terms of engineering-economics and the cost characteristic of conveyor. Besides, it studies the increase of the lowest total cost in case of the conveyor's overdesign value of 50 ton $\mathrm{h}^{-1}$ was added. The results are shown as follows.

The optimum belt width of conveyor could be classified into 2 cases. The first one was the optimum belt width without the turning point of the total cost that occurred when the convey capacity was 50 ton $\mathrm{h}^{-1}$. For this case, the optimum belt width that made the lowest total cost was $400 \mathrm{~mm}$. The other one was the optimum belt width with the turning point of the total cost that occurred when the convey capacity was higher than 50 ton $\mathrm{h}^{-1}$. The lowest total cost of the conveyor occurred at the turning point of the total cost and it was the belt width of $500 \mathrm{~mm}$ for every length and inclination angle. This was because of the effect of the energy cost.

When the conveyor length increased, the conveyor's lowest total cost increased linearly.

When an overdesigned value of 50 ton $\mathrm{h}^{-1}$ was added to the normal convey capacity design of 50 ton $\mathrm{h}^{-1}$, it caused the conveyor's lowest total cost to increase more than $7 \%$. With an overdesigned value of 50 ton $\mathrm{h}^{-1}$ added to normal convey capacity of 100 ton $\mathrm{h}^{-1}$ upward, the lowest total cost increased not more than $2 \%$.

\section{ACKNOWLEDGEMENT}

The researchers would like to show gratitude towards Department of Mechanical Engineering, Faculty of Engineering and Industrial Technology, Silpakorn University for their support. 


\section{REFERENCES}

Bolatturk, A., 2006. Determination of optimum insulation thickness for building walls with respect to various fuels and climate zones in Turkey. Applied Therm. Eng., 26: 1301-1309. DOI: 10.1016/j.applthermaleng.2005.10.019

Fonseca, D.J., G. Uppal and T.J. Greene, 2004. A knowledge-based system for conveyor equipment selection. Expert Syst. Applic., 26: 615-623. DOI: 10.1016/j.eswa.2003.12.011

Hou, Y.F. and Q.R. Meng, 2008. Dynamic characteristics of conveyor belts. J. China. Univ. Mining. Technol., 18: 629-633. DOI: 10.1016/S1006-1266(0 8)60307-7

Jinghua, Y., C. Yang, L. Tian, D. Liao, 2009. A study on optimum insulation thicknesses of external walls in hot summer and cold winter zone of China. Applied Energy, 86: 2520-2529. DOI: 10.1016/j.apenergy.2009.03.010

Ozel, M. and K. Pihtili, 2007. Optimum location and distribution of insulation layers on building walls with various orientations. Build. Environ., 42: 30513059. DOI:10.1016/j.buildenv.2006.07.025

Soylemez, M.S. and M. Unsal, 1999. Optimum insulation thickness for refrigeration applications. Energy Convers. Manage., 40: 13-21. DOI: 10.1016/S0196-8904(98)00125-3
Soponpongpipat, N., P. Jaruyanon and S. Nanetoe, 2010. The thermo-economics analysis of the optimum thickness of double-layer insulation for air conditioning duct. Energy Res. J., 1: 146-151. DOI: 10.3844/erjsp.2010.146.151

Tsalidi, S.S. and A.J. Dentsoras, 1997. Application of design parameters space search for belt conveyor design. Engng. Applic. Artif. Intell., 10: 617-629. DOI: 10.1016/S0952-1976(97)00044-4

Wheeler, C.A., 2008. Design Considerations for Long Overland Conveyors. In: Bulk Material Handling By Conveyor Belt 7, Alspaugh, M.A. (Ed.), Society for Mining, Metallurgy and Exploration, Inc., ISBN-10: 0873352602, pp: 3-12.

Yeunyongkul, P., P. Sakulchangsatjatai and P. Terdtoon, 2010. Mathematical model of the optimum heat pipe heat exchanger for a condenser of vaporcompression refrigeration cycle. Energy Res. J., 1: 104-110. DOI: 10.3844/erjsp.2010.104.110

Zhang, S. and X. Xia, 2011. Modeling and energy efficiency optimization of belt conveyors. Applied Energy, 88: 3061-3071. DOI: 10.1016/j.apenergy.2011.03.015 